\title{
Design of a Sliding PID Controller for The Surge and Roll Motion Control of UNUSAITS AUV
}

\author{
Teguh Herlambang and Hendro Nurhadi
}

\begin{abstract}
The development of underwater vehicle technology is commonly utilized in defences. NKRI needs this technology for applications and multifunctional technology becomes an important thing, since its modernization leads to developed AUV as Republics-of-Indonesia's main weapon is sea defence. This paper proposes motion control system design applying equation of motion with 2 Degree of Freedom (DOF) to AUV system. The equation of AUV motion with 2-DOF covers surge motion and rolling motion is in the form of nonlinear equation. The control system design applied to the system of UNUSAITS AUV uses method of Sliding Proportional Integral Derivative (SPID). The result of SPID control system with the equation of motion with 2-DOF suggested that the stability of the system was reached when the resulted errors on surge motion and rolling motion were respectively $0.002 \%$ and $0.05 \%$.
\end{abstract}

Index Terms-AUV, motion control, sliding PID.

\section{INTRODUCTION}

D EVELOPMENT of underwater vehicle technology commonly utilized in defences. NKRI needs it for applications and multifunctional technology becomes an important thing, since its modernization leads to developed AUV as Republics-of-Indonesia's main weapon is sea defence. Over than $70 \%$, Indonesia is over ocean, so Indonesia potency need attention and good technology is able to determine the full potential of the Indonesians oceans. Underwater robotics technology is very necessary in this case to assist the human to exploration in Indonesian oceans [1].

Underwater robotics technology currently being developed is an Autonomous Underwater Vehicle (AUV). AUV is capably underwater vehicle in moving automatically without direct control by humans according to the trajectory [2]. AUV has an important role for a country that has an ocean region greater than the land region. AUV are widely used for ocean exploration, contourmapping and as a means of defense under the sea [3]. AUV work independently means without direct control by humans. AUV can be used for underwater exploration, mapping, underwater defense system equipment, sensor off board submarines, inspection of underwater structures, natural resources and the condition of the Earth's surface plates etc [4]. Two important things required to analyze the Autonomous Underwater Vehicle (AUV) that is Earth Fixed Frame (EFF) and Body Fixed Frame (BFF).

Manuscript received May 25, 2017; accepted June 13, 2017.

$\mathrm{T}$. Herlambang is with the Department of Information System, Nahdlatul Ulama Surabaya University, Surabaya, Indonesia. Email: teguheunusa.ac.id

H. Nurhadi is with the Department of Mechanical Engineering, Institut Teknologi Sepuluh Nopember, Surabaya 60111, Indonesia. Email: hdnurhadi@me.its.ac.id
This paper is a study on the development of design control systems for AUV. Sliding PID is combination of two control system method are Sliding Mode Control (SMC) and Proportional Integral derivative (PID). The main contribution of this paper is the design control system of UNUSAITS AUV system for surge dan roll motion using Sliding PID (SPID).

The result of this paper is numeric simulation by comparing set-point and the result of SPID to get a small error. This paper consists of two types of simulations in which the first by surge motion and the second by roll motion. Profile of UNUSAITS AUV is depicted in Fig. 1.

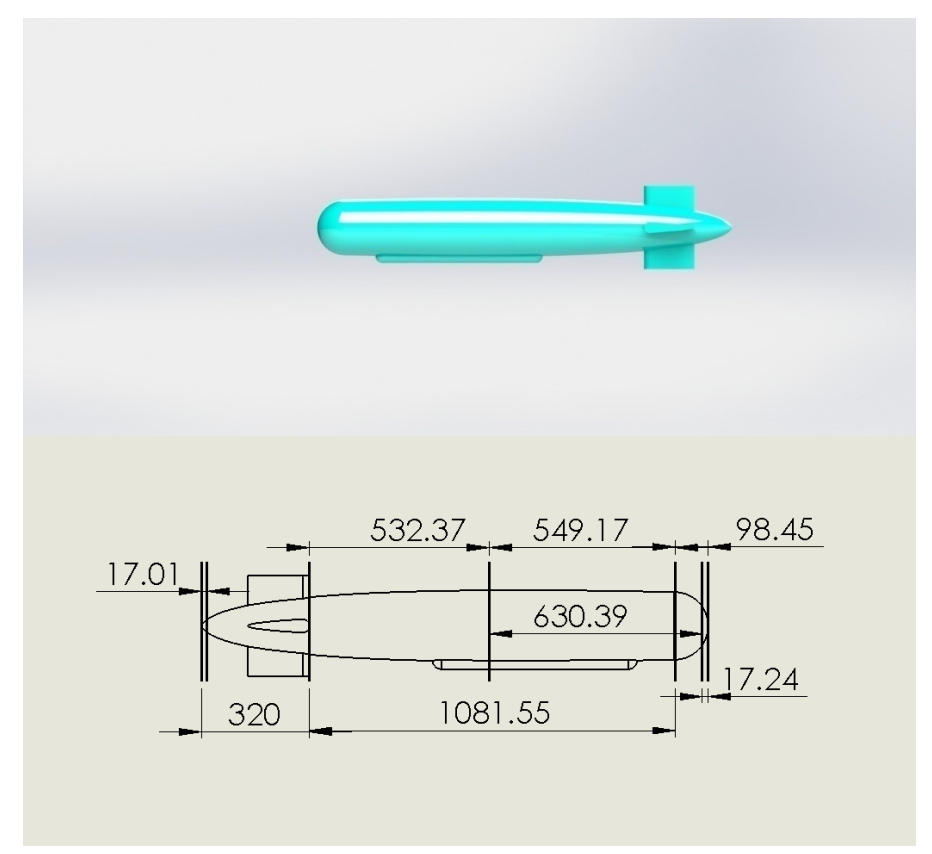

Fig. 1. Profile of UNUSAITS AUV.

\section{Autonomous Underwater Vehicle}

Two important things required to analyze the Autonomous Underwater Vehicle (AUV) that is Earth Fixed Frame (EFF) and Body Fixed Frame (BFF) [5]. EFF is used to describe the position and orientation of the AUV with the position of the $x$-axis to the north, the $y$-axis to the east and the $z$-axis toward the center of the earth while BFF is used to describe the speed and acceleration of the AUV with the starting point at the center of gravity. $x$-axis to the ship's bow, the positive $y$-axis direct to the right side of the ship and the positive $z$-axis direct [6]. This paper is using equation of motion in the form of two Degree of Freedom (2-DOF), those are surge and roll 
motion. General equation of motion in 2-DOF AUV consists of surge and roll motion as follows

$$
\begin{aligned}
\dot{u} & =\frac{X_{\text {res }}+X_{|u| u} u|u|+X_{\text {prop }}}{m-X_{\dot{u}}} \\
\dot{p} & =\frac{K_{r e s}+K_{p|p|} p|p|+K_{\text {prop }}}{I_{x}-K_{\dot{p}}}
\end{aligned}
$$

This type of UNUSAITS AUV using only one propeller on the tail AUV which will produce $X_{\text {res }}$ and $K_{\text {res }}$ are External forces and moments acting on the AUV. Profile and Specification of UNUSAITS AUV are listed in Fig. 2 and Table I.

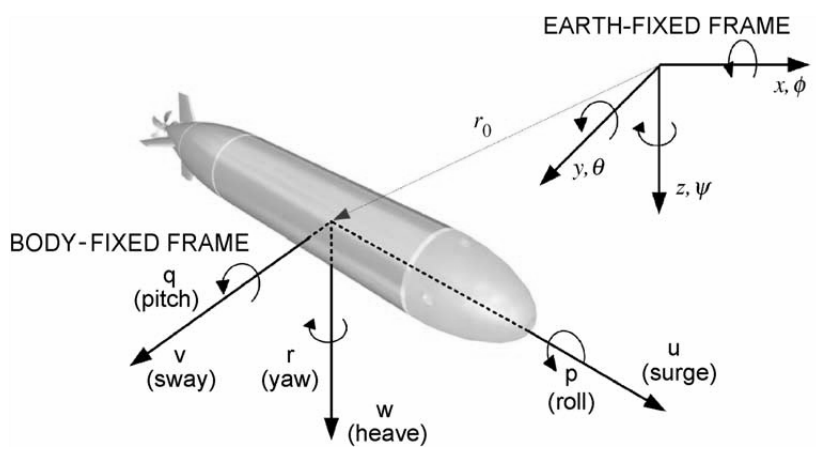

Fig. 2. 6-DOF of AUV [5].

TABLE I

SPECIFICATION OF UNUSAITS AUV [6].

\begin{tabular}{|l|l|}
\hline Weight & $16 \mathrm{Kg}$ \\
\hline Overall lenght & $1500 \mathrm{~mm}$ \\
\hline beam & $200 \mathrm{~mm}$ \\
\hline Controller & Ardupilot Mega 2.0 \\
\hline Comunication & Wireless Xbee $2.4 \mathrm{GHz}$ \\
\hline Camera & TTL Camera \\
\hline Battery & Li-Pro $11,8 \mathrm{~V}$ \\
\hline Propulsion & $12 \mathrm{~V}$ motor DC \\
\hline Propeller & 3 Blades OD $: 50 \mathrm{~mm}$ \\
\hline Speed & 3.1 knots $(1.5 \mathrm{~m} / \mathrm{s})$ \\
\hline
\end{tabular}

\section{Sliding Mode CONTROL}

Sliding Mode Control is a control method based on robust control, which means the system is working to address the problem of modeling uncertainties [7].

\section{A. Switching Function}

Let a dynamic system:

$$
\dot{x}^{(n)}=f(x, t)+b(x, t) u+d(t)
$$

where $u$ is the control input, $x$ is a state vector, $f(x, t)$ and $b(x, t)$ the form of limited functionality, $d(t)$ is the external interference. Switching function that surface $S(x, t)$ in the state space $\mathbb{R}^{n}$, meets the general equation:

$$
S(x, t)=\left(\frac{d}{d t}+\lambda\right)^{n-1} e(t)
$$

Sliding conditions are defined as follows [8], [9]:

$$
\dot{V}=S \dot{S} \leq-\eta|S|
$$

Inequality (5) is called the condition of sliding. The sliding condition can be written in several forms, namely:

$$
\dot{S} \operatorname{sgn}(S) \leq-\eta
$$

\section{SLIDING PID}

Design control system of SPID is combination of SMC and PID. In this research, this system was designed by applying SMC, then optimalized by PID controller as illustrated in the following block diagram in Fig. 3.

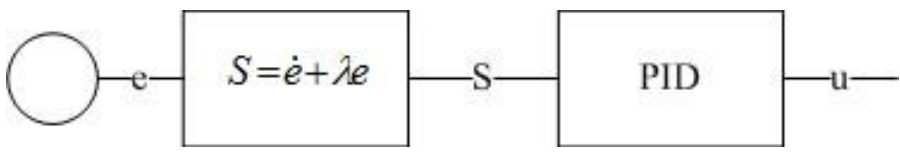

Fig. 3. Block diagram SPID.

\section{Research Methodology}

The research flowchart applied in this paper is as follows:

\section{DESIGN OF CONTROL SYSTEM 2-DOF USING SPID}

In this part, SMC was designed to gain control input for surge and roll motion. To gain control for surge, first tracking error for surge is defined as follows

$$
u_{d}=\text { constant }
$$

For on order system, switching function is formed as follows [10]: $S(u, t)=\left(\frac{d}{d t}\right)^{n-1} \tilde{u}$ with $\mathrm{n}=1$

$$
\begin{aligned}
& S(u, t)=\left(\frac{d}{d t}\right)^{1-1} \tilde{u} \\
& S(u, t)=\tilde{u}=u-u_{d}
\end{aligned}
$$

Whereas, the derivative of $S$ function is :

$$
\dot{S}(u, t)=\dot{u}-\dot{u}_{d}
$$

since $u_{d}$ is a constant then $\dot{u}_{d}=0$. By substituting equation (1) to (6), the results are:

$$
\dot{S}(u, t)=\frac{X_{\text {res }}+X_{|u| u} u|u|+X_{\text {prop }}}{m-X_{\dot{u}}}
$$

And then determining value of $\hat{X}_{\text {prop }}$ from equation (7) with value $\dot{S}=0$

$$
\frac{X_{\text {res }}+X_{|u| u} u|u|+X_{\text {prop }}}{m-X_{\dot{u}}}=0
$$

So we obtain $\hat{X}_{\text {prop }}$ is

$$
\hat{X}_{\text {prop }}=-\left(X_{\text {res }}+X_{|u| u} u|u|\right)
$$

Based on control law fulfilling the sliding condition, the equation is

$$
X_{\text {prop }}=\hat{X}_{\text {prop }}-K_{1} \operatorname{sgn}(S)
$$

In the same way of obtaining the equation of sliding for surge, to design the equation of sliding for roll motion. The same steps were applied to obtain the equation of sliding for roll, the tracking error for roll was first determined as follows: 


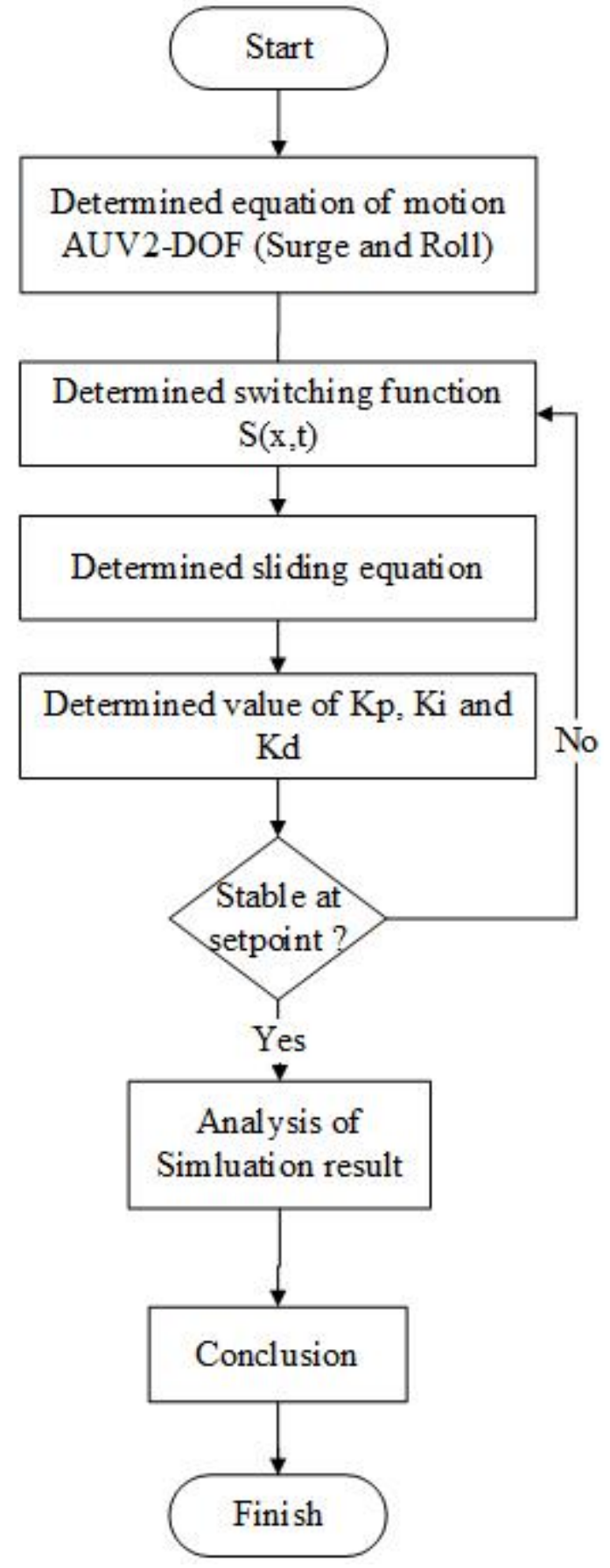

Fig. 4. The research flowchart.

$$
\tilde{p}=p-p_{d}, \quad p_{d}=\text { constant }
$$

For on order system, switching function is formed as follows $S(p, t)=\left(\frac{d}{d t}\right)^{n-1} \tilde{p}$ with $n=1$

$$
\begin{aligned}
& S(p, t)=\left(\frac{d}{d t}\right)^{1-1} \tilde{p} \\
& S(p, t)=\tilde{p}=p-p_{d}
\end{aligned}
$$

whereas, the derivative of $S$ function is

$$
\dot{S}(p, t)=\dot{p}-\dot{p}_{d}
$$

since $p_{d}$ is a constant, then $\dot{p}_{d}=0$. By substituting equation (2) to (11), the results are:

$$
\dot{S}(p, t)=\frac{K_{\text {res }}+K_{p|p|} p|p|+K_{\text {prop }}}{I_{x}-K_{\dot{p}}}
$$

And then determining value of $\hat{K}_{\text {prop }}$ from equation (12) with value $\dot{S}=0$

$$
\frac{K_{r e s}+K_{p|p|} p|p|+K_{\text {prop }}}{I_{x}-K_{\dot{p}}}=0
$$

So we obtain $\hat{K}_{\text {prop }}$ is

$$
\hat{K}_{\text {prop }}=-\left(K_{\text {res }}+K_{p|p|} p|p|\right)
$$

Based on control law fulfilling the sliding condition, the equation is

$$
K_{\text {prop }}=\hat{K}_{\text {prop }}-K \operatorname{sgn}(S)
$$

After the equation of sliding for surge and roll motion were obtained, combination of SMC and PID control system were made, in which PID method is applied to determine the proportional, integral and derivative value that was trial and error. The following is table of PID (Proportional, integral and derivative value).

TABLE II

PROPORTIONAL, INTEGRAL AND DERIVATIVE VALUE OF PID.

\begin{tabular}{|l|l|l|l|}
\hline & \multicolumn{3}{l}{ PID default } \\
\hline & Proportional & Integral & Derivative \\
\hline Surge & 2 & 1.5 & 1.5 \\
\hline Roll & 2.5 & 1 & 1.5 \\
\hline
\end{tabular}

\section{Computational RESUlt}

After SPID control system design by nonlinear model of 2DOF was obtained, it was simulated by simulink Matlab. This control system was connected to the AUV block diagram as close loop as shown in Fig. 5.

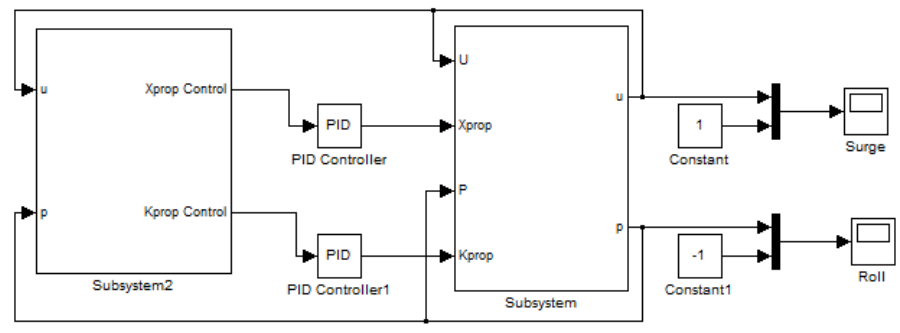

Fig. 5. Block diagram SPID.

After design control system of SPID and AUV were simulated, it generates response for translation and rotation motion shown in Fig. 6 and Fig. 7.

Figure 5 shows the result of SPID response for surge motion. It was observed that the response for surge motion was stable at setpoint $1 \mathrm{~m} / \mathrm{s}$, and it managed to reach settling time of 0.4 second with an error of $0.002 \%$. Whereas, Fig. 6 shows the result of SPID response for roll motion at set point $1 \mathrm{rad} / \mathrm{s}$, and it managed to reach settling time of 0.4 second with error of $0.05 \%$, reaching maximum overshoot $-2.7 \mathrm{rad} / \mathrm{s}$. 


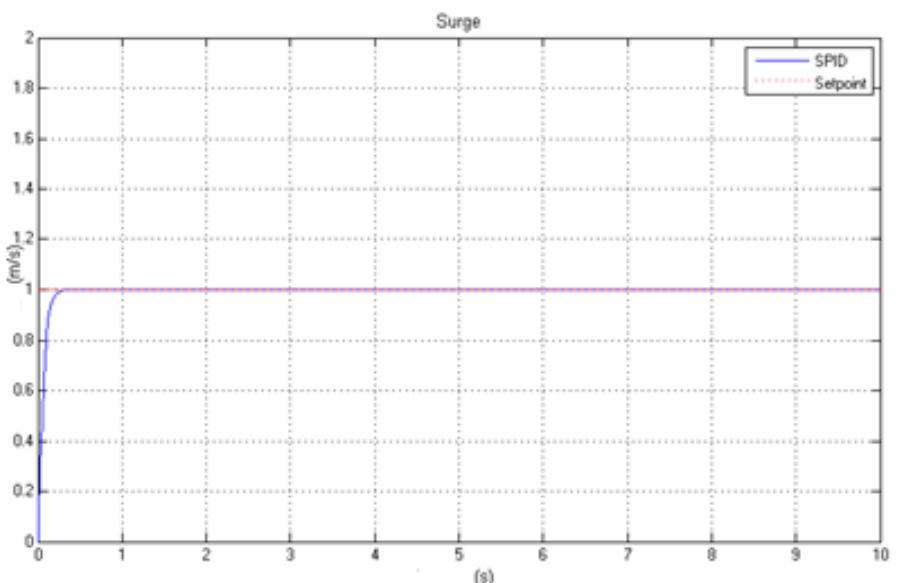

Fig. 6. Surge Motion using SPID.

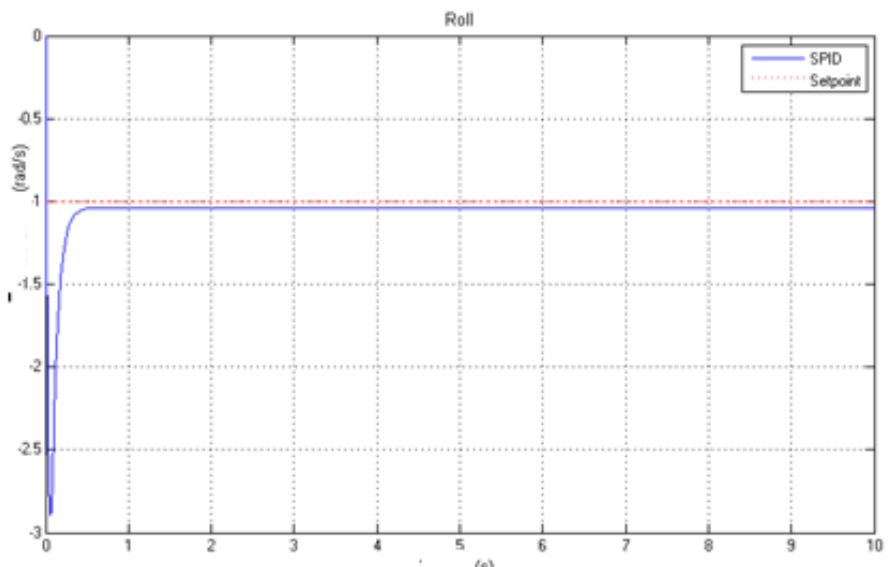

(s)

Fig. 7. Roll Motion using SPID.

\section{CONCLUSION}

Based on the analysis of simulation result, Sliding-PID method could be applied for control system for surge and roll motion with considerably high accuracy. With surge motion error of $0.002 \%$, with settling time of 0.4 second and roll motion error of $0.05 \%$ with settling time of 0.4 second.

\section{REFERENCES}

[1] T. Herlambang, H. Nurhadi, and Subchan, "Preliminary numerical study on designing navigation and stability control systems for ITS AUV," in Applied Mechanics and Materials, vol. 493, 2014, pp. 420-425.

[2] T. Herlambang, E. Djatmiko, and H. Nurhadi, "Ensemble Kalman filter with a square root scheme (enkf-sr) for trajectory estimation of AUV SEGOROGENI ITS," International Review of Mechanical Engineering (IREME), vol. 9, no. 6, pp. 553-560, 2015.

[3] Z. Ermayanti, E. Apriliani, H. Nurhadi, and T. Herlambang, "Estimate and control position autonomous underwater vehicle based on determined trajectory using fuzzy Kalman filter method," in International Conference on Advanced Mechatronics, Intelligent Manufacture, and Industrial Automation (ICAMIMIA), 2015, pp. 156-161.

[4] T. Herlambang, E. Djatmiko, and H. Nurhadi, "Navigation and guidance control system of AUV with trajectory estimation of linear modelling," in International Conference on Advanced Mechatronics, Intelligent Manufacture, and Industrial Automation (ICAMIMIA), 2015, pp. 184187.
[5] C. Yang, "Modular modelling and control for autonomous vehicle (AUV)," Master's thesis, National University of Singapore, Singapore, 2007.

[6] T. Fossen, "A nonlinear unified state-space model for ship maneuvering and control in a seaway," International Journal of Bifurcation and Chaos, vol. 15, no. 9, pp. 2717-2746, 2005.

[7] K. Oktafianto, T. Herlambang, Mardlijah, and H. Nurhadi, "Design of autonomous underwater vehicle motion control using sliding mode control method," in International Conference on Advanced Mechatronics, Intelligent Manufacture, and Industrial Automation (ICAMIMIA), 2015, pp. $162-166$.

[8] T. Herlambang, "Desain sistem kendali gerak surge, sway dan yaw pada autonomous underwater vehicle dengan metode sliding mode control (SMC)," Journal of Mathematics and Its Applications, vol. 14, no. 1 , pp. 53-60, 2017.

[9] T. Herlambang, Mardlijah, E. Apriliani, and H. Cordova, "Dynamic sliding mode control (DSMC) untuk sistem kendali water level pada steam drum boiler," Technology Science and Engineering Journal, vol. 1, no. $1,2017$.

[10] T. Herlambang, H. Nurhadi, and E. Djatmiko, "Optimization of linear model 6-dof in autonomous underwater vehicle," in National Seminar of Maritime, Sciences and Applied Technology (MASTER), Surabaya, ID, Nov. 2016. 